\title{
Changes in endothelial cell density following accidental trauma
}

\author{
M. J. ROPER-HALL, R. S. WILSON, AND S. M. THOMPSON \\ From the Birmingham and Midland Eye Hospital, Church Street, Birmingham B3 2NS
}

SUMMARY Specular photomicroscopy on 25 patients who had accidental perforating injuries affecting the anterior segment of the eye revealed the major cause of cell loss to be the intraocular manipulation of foreign bodies and secondary surgery.

\section{Subjects and methods}

Twenty-five patients were studied, who had attended the Birmingham and Midland Eye Hospital or associated hospital units. They ranged in age from 12 to 77 (mean 32.2) years and the corneal endothelium was studied from 3 months to $15 \cdot 5$ years (mean $25 \cdot 7$ months).

Both eyes of each patient were photographed, 3 or more exposures being taken of each eye, with the Heyer-Schulte specular microscope; fixed-frame counts were made from black-and-white enlargements. The percentage cell density change was recorded as a direct comparison between the traumatised and normal eyes, none of which showed any sympathetic inflammation.

\section{Results}

All the patients had perforating injuries affecting the anterior segment of the eye. Eight patients had injuries from shattered windscreens; 5 patients were hit by thrown objects; 4 sustained lacerations from sharp metal objects; 4 were hit by metal when hammering, including 3 with posterior segment intraocular foreign bodies. Two had lacerations from broken spectacles, one suffered a perforation from hot metal and one walked into a ladder.

Of the 3 patients who had posterior segment foreign bodies 2 had the foreign body removed as a late procedure, which involved no anterior segment surgery. All other patients underwent emergency corneal repair within 24 hours.

The average drop in cell count was $14.75 \%$ (SD

Correspondence to Mr M. J. Roper-Hall
$19 \cdot 08)$, of which 14 patients (56\%) had a drop of less than $10 \%$. Out of 18 patients in whom the depth of the anterior chamber was noted at presentation to the hospital 3 were recorded as having flat anterior chambers. They showed a cell loss of $12 \cdot 36 \%$, which is not significantly different from those 15 with formed anterior chambers $(13 \cdot 6 \%)$.

Seven patients had lens surgery. One had lens aspiration at the first procedure with a cell loss of $3.5 \%$. Three had lens aspiration/irrigation as a late procedure and had an average cell loss of $22.9 \%$. One patient underwent a lensectomy/vitrectomy, which was complicated by a wound leak requiring a secondary repair, and had a cell loss of $41 \cdot 6 \%$. One patient required a late needling following a lens aspiration at the original repair and had a cell loss of $72 \cdot 5 \%$. One patient had a corneal and lens perforation from a piece of metal which was subsequently removed through a sclerotomy without any anterior segment repair. Two years later he underwent an intracapsular cataract extraction with insertion of a Binkhorst 4-loop intraocular lens, during which there was no contact with the endothelium. He was recorded 10 months later as having a cell loss of $34 \cdot 3 \%$.

The average cell loss of those cases without secondary lens surgery was $7.9 \%(n=19)$ and those cases with secondary surgery was $36 \cdot 19 \%(n=6)$, which is highly significant $(\mathrm{p}<0 \cdot 01)$.

Three cases had foreign material in the anterior chamber. Two had glass and one had glass and lashes. The average cell loss for these 3 was $21 \cdot 7 \%$.

Apart from the 3 cases above and those cases which had secondary lens surgery 9 cases had lacerations extending less than half the corneal diameter, with an average cell loss of $3.7 \%$, and 5 had lacerations 
Table 1 Results

\begin{tabular}{llccc}
\hline & & Number & \% drop & Significance \\
\hline Anterior chamber depth & Flat & 3 & 12.35 & Nil \\
Secondary lens surgery & Formed & 15 & 13.6 & \\
& Yes & 6 & 36.19 & p \\
Extent of laceration & No & 19 & 7.98 & \\
& > Half & 5 & 5.33 & Nil \\
\hline
\end{tabular}

extending for more than half the corneal diameter, with an average cell loss of $5.33 \%$. The difference between these 2 groups is not significant (Table 1).

\section{Discussion}

Comparison of operated with unoperated eyes for estimation of changes in endothelial cell densities has been shown to correlate closely with pre- and postoperative counts in unilateral cataract surgery. ' It has been necessary to assume a similar correlation holds for accidental trauma, where no earlier cell counts were available. No cases were studied earlier than 3 months after the final procedure, as this has been found to be the period after which little alteration in cell density occurs. ${ }^{2}$

Studies of surgical trauma in planned cataract surgery and intraocular lens implantation reveal that direct endothelial damage is the major cause of cell loss. ${ }^{34}$ To a lesser degree cells are lost by the cytotoxic nature of various substances on the endothelium, which may be introduced into the anterior chamber. ${ }^{56}$

Slingsby and Forstot ${ }^{7}$ have shown that blunt corneal trauma, without any entry into the anterior chamber, can have a significant effect on endothelial cell density, although this difference is small, $6.4 \%$ loss in a series of 25 patients. The cell loss, which we have found in a similar number of patients with penetrating injuries, was smaller than would be expected, as each patient, in addition to a significant contusion to the globe, would have received a variable amount of intraocular manipulation. It was only when extensive endothelial trauma occurred, either from traumatically implanted foreign bodies or when secondary surgery was performed, that large drops in cell density were found.

There are points to be clarified by a more extensive prospective study. We have found a wide range of results, over which the average has been taken. Larger numbers of subjects may have an effect on the overall result. More detailed monitoring should be made of the instrumentation and fluids used within the anterior chamber during the primary and secondary surgical procedures.

The cases which have had secondary procedures have widely differing changes in cell density, and it may be that the endothelium, which is in the process of migrating to cover bare areas, has an increased susceptibility to further trauma during the secondary procedure. Although the original cell loss is small in uncomplicated perforating injuries, a secondary procedure-for example, a secondary combined lens aspiration with intraocular lens insertion-may result in considerably greater cell loss than would be expected were this to be carried out as a primary procedure on a previously untraumatised eye.

\section{References}

1 Roper-Hall MJ, Wilson RS. Reduction in endothelial cell density following cataract extraction and intraocular lens implantation. $\mathrm{Br}$ J Ophthalmol 1982; 66: 516-517.

2 Galin MA, Lin LL, Fetherholf E, Obstbaum SA, Sugar A. Time analysis of corneal endothelial cell density after cataract extraction. Am J Ophthalmol 1979; 88: 93-6.

3 Kraff MC, Sanders DR, Lieberman HL. Specular microscopy in cataract and intraocular lens patients. Arch Ophthalmol 1980; 98: 1782-4.

4 Sugar J, Mitchelson J, Kraff M. Endothelial trauma and cell loss from intraocular lens insertion. Arch Ophthalmol 1978; 96: 449-50.

5 Green K. Effect of chlorhexidine on rabbit corneal endothelium. Arch Ophthalmol 1980; 98: 1273-8.

6 Vaughn ED. Effect of intraocular miotics on corneal endothelium. Arch Ophthalmol 1978; 96: 1897-900.

7 Slingsby JG, Forstot SL. Effect of blunt trauma on the corneal endothelium. Arch Ophthalmol 1981; 99: 1041-3. 